\title{
Factors Influencing the Successful Entrepreneurship of Computer Science Major Students
}

\author{
Zhong Wenbin $^{1}$, Lei Zhiqiang ${ }^{2}$, Gui Wei ${ }^{3^{*}}$ \\ ${ }^{1 .}$ School of Computing,Jiangxi University of Traditional Chinese Medicine, 818 Meiling Road, \\ Nanchang 330004, Jiangxi, P.R. China ; \\ 2. The Office of Students' Financial Assistance, Jiangxi University of Traditional Chinese Medicine, \\ 818 Meiling Road, Nanchang 330004, Jiangxi, P.R. China ; . \\ ${ }^{3}$ School of Humanities, Jiangxi University of Traditional Chinese Medicine, 818 Meiling Road, \\ Nanchang 330004, Jiangxi, P.R. China ; \\ *Corresponding author: Gui Wei .Email:178369210@qq.com
}

Keywords: Computer science major; Entrepreneurship; Affecting factors

\begin{abstract}
With the constant progress of social economy, the relationship between science, technology and commodity is increasingly close. The transformation cycle of scientific and technological achievements into real productive forces has been shortened, and the innovation of science and technology has become the important factor for the sustainable development of social economy. Entrepreneurship innovation education in colleges and universities is to meet the present situation of social economy education, create a new education model and talent training philosophy, and open for all the students. But at this stage, college students' entrepreneurial success is not much, which reduces the efficiency of innovation entrepreneurship. Based on this, this article mainly studies the factors affecting students' successful entrepreneurship by taking computer science major students for example.

Since university enrollment expansion in China, college students' employment problem has been one of the hot social topics. In addition to sustaining growth of graduates each year, graduates' major distribution is also a prominent problem. According to statistics, larger number of graduates is from trade, English, management and other majors, and computer science major is hot because today is network society, so there is an increasing demand for computer science major graduates. However, there is often a requirement for working experience, which affects graduates' application for jobs. Based on this, choosing entrepreneurship is the only way to solve the problem.
\end{abstract}

\section{Computer science major college students' entrepreneurship present situation investigation}

To be able to fully study the related factors influencing computer science major students' successful entrepreneurship, the present situation of computer science major college students' innovation entrepreneurship education has been investigated and analyzed. According to the investigation, there are $55.4 \%$ of the interviewed students understand innovation entrepreneurship, and there are $44.6 \%$ of the students do not understand innovation entrepreneurship. This means that now college students don't know what innovation is or they have no awareness about innovation. There are $28.17 \%$ of the students think that innovation entrepreneurship education is not necessary, which means that students didn't realize the importance of entrepreneurship, which reflects modern computer science major innovation entrepreneurship education quality needs to be further strengthened.

College students hold positive attitudes towards entrepreneurship and more than half of the students agree and support it. Even so, the number of students choosing startups is unsatisfactory. A survey of Tsinghua university entrepreneurship center said that Chinese college students' entrepreneurial activities average level held a lower position in global entrepreneurship monitor statistics. Our survey also reflected that computer science major students' entrepreneurial awareness was low. In choosing business areas, $17.84 \%$ of students choose to venture less investment, and 
there are $57.75 \%$ of the students choose their interest areas for business. There are $24.41 \%$ of the students choose their professional fields related business. It can be seen that students still respect more of their own opinions in choosing entrepreneurship, and can combine their major and interests. From the aspects of market operation, this option requires students to have high professional knowledge. If they can succeed in business survival, the project has greater possibility of long-term operation. [1]

\section{The present entrepreneurial situation of university students in our country}

After the enrollment expansion of colleges and universities in our country, higher education gradually enters a large popularization stage, and the number of graduates is growing every year. College students' employment problem has presented a more and more difficult trend. In the process of constant change of economic structure in China, enterprises' demand for talent has been changed. As the number of graduates increasing year by year, the pressure of graduates is becoming bigger and bigger, which leads to more and more talents with high knowledge and social cognitive ability take entrepreneurship as a graduate target. Students' entrepreneur group also gradually entered people's field of vision. College students' entrepreneurship is an important way of promoting university students to realize self value, and can effectively solve difficult university students' employment in China.

At present college students' entrepreneurship in our country has two phenomenons. One is that most of them are in the form of team entrepreneurship. College students' study and live on campus for a long time, and they are not very familiar with the various rules of entrepreneurship, business and society, and are lack of the ability of marketing, finance, communication, management and other aspects, so if they want to succeed, team entrepreneurship is a wise choice. Through understanding, university students can organize students of different major and ability together and divide labor for cooperation business together. In recent years, school competition trends tell us that business competition and business practices are in team form, and fight alone college students' entrepreneurship is not common. Second, entrepreneurial network industry is given priority. With the continuous development of our social economy, the Internet has been spread in the society. Students, in recent years, have become the main use body of network and network activity. Especially after "Internet + " marketing model and concept have been proposed, college students realize that there are great business opportunities behind the Internet, and they just move to network aspects entrepreneurial projects, "Mutual benefit net + service", "Internet + industry" and other venture capital and have made corresponding results, which also attracts the attention of contemporary college students on Internet industry. [2]

But in the process of college students' entrepreneurship, there are a variety of factors leading to the failure of college students' entrepreneurship.

\section{The related factors influencing computer science major students' successful entrepreneurship}

\section{Personal factors.}

The primary reason affecting college students' successful entrepreneurship is their own problems. Entrepreneurship embodies the comprehensive quality of the individual, and it is also a combination of individual learning knowledge and conjoint ability process, which moves from theory to independent operation. Although college students have stronger theoretical basis, learning ability and passion, this is the first step into society, and they have no practical experience, which causes unfavorable factors in entrepreneurial process. First, there is no real role. College students are in the position of students thinking and they think that entrepreneurship is a kind of ways to exercise themselves, but they do not consider that interest is a real corporate goal. This reason is that currently in the process of entrepreneurship, though venture investors are impressed with the business plan, but the students fail to win the trust of investors, leading to financing problems. Second, they lack management experience. Now in the society, an enterprise wants sustainable development. First, it should have high efficiency management system to ensure the enterprise 
rational allocation of resources, fully arouse the enthusiasm of staff in the enterprise, and enable staff to better service for the user. But the current college students' management skills learned in school and college is the theory knowledge, lack of practical management experience, which leads to trouble in their own enterprises and affects entrepreneurial success because students have no management experience in entrepreneurial process.

\section{Insufficiency of venture capital.}

As we all know, computer profession belongs to high-tech industry. The start and development of project mainly depend on money, good ideas and credit support. But the economic source of college students is mainly parents and family support, so the main problem in present college students' entrepreneurship is a shortage of funds. To some extent, this also kills some college students' entrepreneurial dreams. In addition, computer science major students have good ideas, but the ability of the overall project needs to be strengthened. [3]

\section{Insufficient market consciousness.}

The present common problem of college students is insufficient market consciousness and lack of profitability. In computer science, students' learning goal is mainly to give priority to technology, and the education process in colleges and universities lacks the cultivation of student's market consciousness. When students are negotiating with entrepreneurs, entrepreneurs will only talk about how your product technology is advanced and unique, often ignoring the market positioning and market demand of product technology. This can result in the failure of the project entering the market and reduce the chances of success.

\section{Lack of perseverance.}

Entrepreneurship is a matter of willpower. No one can start entrepreneurs successfully. Especially for computer science major, start-up is a protracted war. Modern college students lack the spirit of perseverance and perseverance, which leads to fewer and fewer people can stick to it. Students will only start holding entrepreneurial enthusiasm and gives it up midway when meeting setbacks or difficulties.

\section{Lack of technical value.}

According to the survey, in current computer science major entrepreneurial process, industry and technology developed by student are generally lack of technical content, and basically are hardware maintenance, Taobao, online store, etc. The development of high-tech industry is generally small; resulting in industry lacks competition ability, which reduces the students' entrepreneurial success. [4]

\section{Improve entrepreneurial success way of computer science major college students}

From the objective aspect, the process of college students' entrepreneurship has high risk and difficulties. Computer science major students must have high professional quality and comprehensive quality to search for new projects. Rationally analyze market economy status in the society to achieve their purpose. The success experience is not duplicative, but we can find a successful way to improve college students' entrepreneurship.

\section{Attach importance to college students' entrepreneurship education.}

To entrepreneurial university students, each factor will affect the quality of entrepreneurship. So, to enable students to continue to start up business and improve the record of successful entrepreneurs, we should attach great importance to entrepreneurship education of college students. Improve college students' entrepreneurial skills from each factor affecting college students' entrepreneurship. First, in terms of college students themselves, enhance students' own quality through personal experience and business practice, and find problems and solve them in the process of practice. Make students have pioneering consciousness and exercise their own ability; Second, colleges and universities should strengthen practice teaching, implement college students' social practice activities, guide college students' entrepreneurship to improve college students' entrepreneurial quality. [5] 


\section{Have patience and confidence.}

Computer science and other major students are different. There is no formal education undertaking during college, so there are many setbacks and difficulties in the way. This is to test students' perseverance, asking the students to be with a strong heart and confidence, so that the students do not flinch when facing with difficulties and get step by step to success. It also requires students to have a bold heart, not afraid of failure, exquisite heart, to find right project. Understand the fond of everybody by observing the movements of people to meet their needs. Computer program entrepreneurship also requires staff with a keen eye to timely grasp market trends and needs to develop their own business model, find business opportunities, and improve their commercial value of the company.

Have higher comprehensive ability.

Computer science major students are required to have a solid foundation and self-study ability at the early stage of the business. Entrepreneurs must complete a series of things by themselves in the prophase. In addition, if the business is a team activity, it requires that business personnel have management ability and coordination skills.

\section{Grasp financing opportunities.}

Computer industry technology has high mortality, so business personnel must make comprehensive evaluation and analysis on the market in early stage and make comprehensive exploration. In the process of seeking cooperation or funding, be able to use their mastery comprehensive information to gain financing opportunities. [6]

\section{Conclusion}

In this article, through the analyses of the current situation of college students' entrepreneurship, computer science major students' entrepreneurial success factors are analyzed. According to the influencing factors, a variety of ways are proposed to improve entrepreneurial success to provide a good reference for the future entrepreneurship students. Students are encouraged to start up business and reduce contemporary university students' employment pressure. Business way is not plain sailing, but be ready at an early stage of the business, enhance the confidence and inner heart, and improve the ability of startups and system. These will greatly improve the success probability of entrepreneurship.

\section{Reference}

[1] Wang Lan. College computer science major students' innovation entrepreneurial education model research [D]. Southwest Jiaotong Uuniversity, 2011.

[2] Li Xiaolei. Computer science major college students' entrepreneurial success factor analysis [J]. Journal of Information Science and Technology, 2012 (32) : 195-195.

[3] Lu Xiaohua. Factors affect college students' entrepreneurial intention analysis and countermeasures, based on computer science major graduates of a university in recent five years survey [J]. Science Tribune, 2016 (11).

[4] Qi Xiaojun, Chen Yuangang, Liang Jin. College students' perceptions of factors influencing entrepreneurial success [J]. Journal of Wit, 2013 (31) : 94-95.

[5] Zhang Haiyan. Factors affect college students' entrepreneurial success [J]. Chinese Market, 2016 (14) : 171-172.

[6] Liu Xingbin, Li Yulin, Li Qiang. Factor analysis and countermeasures affecting college students' entrepreneurial success [J]. Journal of School Party Construction and Ideological Education, 2010 (20) : 92-93. 